\title{
THE LEARNING ORGANIZATION - AN ANSWER TO THE CHALLENGES OF THE ACTUAL BUSINESS ENVIRONMENT?
}

\author{
Alexandra Luciana Guță \\ Alexandru Ioan Cuza University of Iași, România \\ luciana_guta@yahoo.com
}

\begin{abstract}
In a knowledge society and a knowledge economy organizations need to have sustainable competitive advantages against their competitors, they need to innovate and to have performance. Organizational learning is a way to achieve these features, because, through organizational learning the intellectual capital of an organization can be developed. The learning organization is an ideal type of organization that learns. After briefly presenting the concepts of "learning organization", "organizational learning", "individual learning", and classifications of types of learning from different perspectives, the article presents managerial adaptations, starting from the actions that an organization has to undertake in order to become a learning organization. Then, it emphasizes the fact that the learning organization is an ideal type of organization, thus managers should first make efforts in the sense of creating conditions that could enable organizational learning and then for turning the organization into a learning organization.
\end{abstract}

Keywords: Learning organization, organizational learning, managerial adaptations, learning processes JEL Classification: D83

\section{INTRODUCTION}

The knowledge society and the knowledge economy are two related concepts. Although the roots of these concepts go back to almost a century ago, when the importance of knowledge for economic growth was emphasized (Hayek, 1937 in Välimaa and Hoffman, 2008, p. 269), these two concepts have gained in importance in recent times. The knowledge society and the knowledge economy have a key characteristic - sustainable economic growth. The business environment is a core element of any economy, so we can say that economic growth is directly connected and interdependent with the business environment.

In the actual knowledge society and knowledge economy, the business environment is more unpredictable than ever. The pace of change is alert. For companies to survive and to prosper in this environment, they need to have sustainable competitive advantages against their competitors, they need to constantly innovate and, implicitly, to have performance at organizational level. Some authors claim that "the essence of the management process is constant directing of changes and constant adaptation to changing environmental conditions" (Cymanow, n.d., p. 1). 


\section{ORGANIZATIONS AND THE KNOWLEDGE SOCIETY AND KNOWLEDGE ECONOMY}

\subsection{Organizations in a knowledge society and a knowledge economy}

In the actual business environment, the competitive advantages that organizations have against their competitors have shorter lifespans than before. This is because the knowledge economy presumes "an accelerated pace of technical and scientific advance, as well as rapid obsolescence" (Powell and Snellman, 2004, p. 199). Thus, the only truly sustainable competitive advantage that organizations have is knowledge. Knowledge is directly linked to the intellectual capital that an organization has, to the competencies that its human resources own. For these competencies to develop, organizations should nurture a learning culture (Murray and Donegan, 2003). We can see that, when linking the concepts of knowledge society, knowledge economy, business environment, knowledge itself and the world of organizations, the common feature is learning.

We will further focus on the concepts of "organizational learning" and especially "the learning organization", as two core concepts that need to be paid attention in the actual business environment.

\subsection{The learning organization and organizational learning}

The importance of knowledge and of learning at organizational level can be easily argued if we take into consideration the fact that organizations confront, in a society that is based on knowledge, with three main challenges: intensification of competition, increased power of customer and shortened life cycles of products (Wang and Ahmed, 2003).

In their beginnings, the terms of "organizational learning" and "learning organization" were used interchangeable, but now there are clear distinctions between the two concepts.

Organizational learning was first used as a concept in 1963, by Cyert and March although the interest in this concept dates to more recent times, in the early 1990s (Marshall, Smith and Buxton, 2009). Despite the many definitions that the concept of "organizational learning" had, it is now generally accepted that learning can be defined as a change in beliefs, in cognitions or in the way of acting, of behaving (Earterby-Smith, Crossan and Niccolini, 2000 in Argote, 2011, p. 440). 
The learning organization is an organization that has the capacity to excel in collective learning, while organizational learning is a set of learning processes. The literature states that, while organizational learning is an activity that an organization undertakes (Tsang, 1997 in Marshall, Smith and Buxton, 2009), the learning organization is a type of organization (Tsang, 1997 in Marshall, Smith and Buxton, 2009) that has inclinations towards learning at organizational level or excels at it (Marshall, Smith and Buxton, 2009).

\subsection{Individual and organizational learning}

The link between individual learning and organizational learning is a controversial one and also one of the most debated subjects in the literature regarding organizational learning. Some authors claim that "organizational learning is the product of individuals' learning" (Argyris and Schön, 1978; Fiol and Lyles, 1985; Senge, 1990 in Antonacopoulou, 2006, p. 456) while other authors appreciate the fact that organizational learning is more than the sum of the members' individual learning in an organization (Crossan, Lane and White, 1999; March and Olsen, 1976; Simon, 1991 in Casey, 2005, p. 132).

In this paper, we will consider that organizational learning is more than the sum of the members' individual learning in an organization. We thus agree with the idea that "the whole is more than the sum of the single parties" (Senge, 2006 in Ameli and Kayes, 2011, p. 176).

It is also argumented that, although employees may leave an organization at some point, what they have learned at individual or team level does not necessarily leave as they leave the organization. This is because a part of what they have learned may be embedded in systems, routines or strategies in organizations (Chiva, Grandío and Alegre, 2010).

\subsection{Classifying organizational learning types}

In the literature regarding organizational learning there are several classifications regarding the types of learning at organizational level. Different classifications of learning types have been summarized (Chiva, Grandío and Alegre, 2010): single and double loop learning (Argyris and Schön, 1974 in Chiva, Grandío and Alegre, 2010), adaptive and generative learning (Argyris and Schön, 1974, 1978; Fiol and Lyles, 1985; Senge, 1990; Lant and Mezias, 1992; Virany, Tushman and Romanelli, 1992; Sitkin, 1996 in Chiva, Grandío and Alegre, 2010), lower and higher level learning (Fiol and Lyles, 1985 in Chiva, Grandío and Alegre, 2010). 
Single loop learning implies that an organization will seek to achieve its goals by adjusting its behaviors. It also presumes that the organization maintains its policies. Double loop learning implies that an organization modifies its norms or policies (Chiva, Grandío and Alegre, 2010), when necessary. In other words, when something does not go as expected, the organization is not going to try and change the situation just by adapting behaviors within the existing norms or policies, but the organization is going to see if it can achieve its objectives by changing the existing norms or policies. Besides single loop learning and double loop learning, another type of learning can be added - triple loop learning. Triple loop learning has a vague nature. It is claimed that triple loop learning means "an additional level of learning that considers an external partner's values and strategies" (Ameli and Kayes, 2011, p. 176). The authors also state that the nature of triple loop learning is not precise, according to the literature - "some authors affirm that it is concerned with new structures and strategies for learning", "while other authors contend that triple-loop learning is a learning process related to ethical behaviors" (Ameli and Kayes, 2011, p. 176).

Adaptive and generative learning are similar to single loop learning and, respectively, to double loop learning. Adaptive learning means that organizations can improve their existing competencies or technologies but without necessarily examining their beliefs. Generative learning implies that organizations are able to see beyond a certain situation and to question the operating norms (Chiva, Grandío and Alegre, 2010). While adaptive learning means to react in an automatical way to stimuli, generative learning implies to learn pro-actively and intentionally and to apply new knowledge or behaviors (Sessa et al., 2011). Another type of learning can be added to this classification - transformative learning. Transformative learning implies "experiencing disorientation and then reorientation for an entirely new direction for growth" (Sessa et al., 2011, p. 149).

The last clasification that we have taken into consideration refers to lower and higher level learning. The first type implies that organizations repeat past behaviors, while higher level learning means that organizations will develop complex rules related to new actions.

\section{THE LEARNING ORGANIZATION - WHAT CAN MANAGERS DO TO TRANSFORM AN ORGANIZATION INTO A LEARNING ORGANIZATION}

"Learning organizations [are] organizations where people continually expand their capacity to create the results they truly desire, where new and expansive patterns of thinking are nurtured, 
where collective aspiration is set free, and where people are continually learning to see the whole together." (Senge, 1990 in Smith, 2001).

Learning organizations have a series of characteristics: "Provide continuous learning opportunities. Use learning to reach their goals. Link individual performance with organizational performance. Foster inquiry and dialogue, making it safe for people to share openly and take risks. Embrace creative tension as a source of energy and renewal. Are continuously aware of and interact with their environment." (Kerka, 1995 in Smith, 2001).

From the ideas that have been previously exposed we can consider that a learning organization is more prepared to face the challenges of the knowledge society, the knowledge economy and, implicitly, of the actual business environment.

In order for a traditional organization to turn into a learning organization, a series of actions has to be undertaken. In order for these actions to be undertaken, some managerial adaptations must be made.

A series of levels and competing values in learning organizations have been considered in the literature (Loverde, 2005), from which derives a series of actions that can be undertaken. The author further makes a detailed comparison between the characteristics of a traditional organization and of a learning organization, from which a series of managerial adaptations can be drawn.

We must mention that Loverde refers to these actions from the point of view of learning organizations with different levels of feedback: single - loop feedback, double - loop feedback, triple - loop feedback, quadruple - loop feedback but we will consider that the transformations that we will further present, from the work of Loverde, can also be seen as enablers for turning a traditional organization into a learning organization.

First, a part of the management levels have to be removed and orizontal structures and/ or smaller business units need to be created, business units that need to focus on key competencies. This has to be combined with vertical intelligence, which means that managers need to integrate the principles, values and judgments and to have a deep understanding of the causes and foundations of certain actions. Second, different cultures, races, genders and sexual orientations need to thrive in a company because complex and adaptive systems evolve better when more options are competing in nearly chaotic conditions. Each person must be permitted to speak according to its traditions, goals and needs and in the end the differences need to be reconciled. Being aware of the importance that tacit knowledge has is the third action that needs to be undertaken. The awareness of the importance of tacit knowledge is needed because, if we focus exclusively on explicit knowledge, we marginalize or even exclude anything and anybody that does not fit the current paradigm. Explicit 
knowledge is knowledge that can be easily codified or expressed in a formal or a systematic language (Tiwana, 1999 in Brătianu and Orzea, 2008, p. 125). Tacit knowledge is more personal, it is contextual, being embedded in humans' minds (Brătianu and Orzea, 2008) or in the routines of an organization (Howitt, 1996 in Oxley et al., 2008). Tacit knowledge, unlike explicit knowledge, is hard to express, difficult to formalizare or to share with other persons (Nonaka and Konno, 1998). The next aspect targets the elimination of benchmarking and the improvement of old methods. The focus must be on finding new methods, which stimulates innovation. Further, the accent should be on emotional skills and not on intellectual skills. Skills in the emotional area are needed in order to manage change. Without such skills, people may become fearful and irritable when dealing with changes. And finally, a transition must be made, from the accumulation and transfer of knowledge to implementing knowledge in an active way, which involves a shift from an explicit "know what" to an implicit "know how" and even to "know why", in order to create new knowledge through discovery and innovation.

In order for these kinds of actions to take place in an organization, managers need to make some adaptations, in order to facilitate the metamorphosis of a traditional organization into a learning organization. Further, we will present a few of all the adaptations that managers could do in order to transform a traditional organization into a learning organization. The work presented by Loverde is more detailed, presenting a comparison between a traditional corporation and a learning one.

First, managers should change the conception according to which learning is individual, procedures are dominant and new staff should have achievements according to the existent standards of performance. This way, the accumulation of knowledge becomes a collaborative process and intelligence is collective. What the organization learns is shared by all its members and the main challenge is that all employees are able to create high performance standards. This can be materialized through team projects and learning implemented at team level. Another important element is that teams should manage themselves, leading to the concepts of "self - managed teams".

Also, managers should make a transition from a passive learning style, when it is considered that the data is complete and we just have to manage it, to an active learning style, when managers realize that the available data is incomplete and it is not going to provide enough information to support performance. Thus, people must learn harder in order to achieve excellence.

One important thing that managers should do in order to transform a traditional organization into a learning one is to find new ways of doing things and not just improve old methods. So, 
managers need to make a transition from rigid objectives and procedures that are implemented in order to control, to revise objectives and procedures, in the sense that no one can know for sure which are the best methods to do what needs to be done.

The emphasis should not be on dissemination of information in order for employees to memorize it, but on learning how to learn, taking into consideration the fact that the situations that organizations confront with are increasingly diverse and they must be addressed in an optimal way.

Then, managers should adapt their behavior in order to make a transition from the role of supervisors in terms of authority - when they know what needs to be done and make sure that things are done as they want them to be done, to the role of teachers or guides - each employee explores better and better methods to do things.

Another change that managers must undertake in order to transform a traditional organization into a learning organization is in terms of how knowledge is being measured, regarding the knowledge gained by both managers and employees. The transition should be from measuring knowledge by testing the degree of learning to measuring goal achievements, also taking into consideration the fact that data is fragmentary and in constant change.

Regarding the considered time frame, the change should be from developing short term competencies, which help to achieve simple tasks, to developing long term competencies and the ability to face complexity, to find solutions for certain situations that occur in an organization, in the market and in the socio - economic environment, these being in a constant change.

The last change that we will detail, although not the last one in importance, is changing the conception regarding the cultural context. The emphasis should be not on cultural homogeneity but on cultural diversity, the last one being able to facilitate the process of learning in organizations.

\section{IS THE LEARNING ORGANIZATION THE ANSWER? ENABLING} ORGANIZATIONAL LEARNING

Taking into consideration the fact that in the knowledge society and knowledge economy, the knowledge that an organization owns is one of its few sustainable competitive advantages, the importance of learning at organizational level is increasing. Apparently, the learning organization is the answer to the actual business environment, which is characterized through constant changes. But we need to take into consideration that the learning organization is an ideal type of organization that learns. In reality, we support the idea that managers should first act in such a way that they enable organizational learning processes. 
A series of classifications appears in the literature regarding the sub-processes of organizational learning. Lytras and Pouloudi (2003) have made a synthesis of these sub-processes, although they do not refer to them as organizational learning sub-processes, but as knowledge management life cycles models. Another author classifies these sub-processes in: creation, retention and transfer of knowledge (Argote, 2011).

No matter which of the sub-processes of organizational learning we take into consideration, there is a series of factors that can facilitate or inhibit organizational learning. In order for organizations to develop a process of organizational learning, managers must create conditions; they must enable the occurrence of facilitating factors for organizational learning.

The literature regarding the facilitating and inhibiting factors of organizational learning is extensive. We will further present a series of factors, for a better understanding of the context.

In the case of the knowledge creation sub-process, one of the most well known models in the literature regarding knowledge management is the SECI model (Nonaka, 1994; Nonaka and Takeuchi, 1995; Nonaka and Konno, 1998). The authors propose that new knowledge is being created by continuum conversions between tacit and explicit knowledge, along four steps: socialization - individuals share tacit knowledge, externalization - the sum of the individuals' ideas integrate at the group level and tacit knowledge becomes explicit knowledge, combination - from group level to organizational level; implies "the conversion of explicit knowledge into more complex sets of explicit knowledge" (Nonaka and Konno, 1998, p. 44) and internalization - this last step takes place at organizational level and means that explicit knowledge is conversed into tacit knowledge. We have briefly presented the SECI model because it is corelated with the concept of $\mathrm{Ba}$. According to the authors, $\mathrm{Ba}$ is a space for the creation of knowledge. Ba can be a physical, mental of virtual space or a combination of these. Each of the four steps of the SECI model has a correspondent $\mathrm{Ba}$ : socialization - originating ba, externalization - interacting ba, combination cyber ba and internalization - exercising ba.

Six organizational factors are discussed (Nonaka and Takeuchi, 1995), factors that can enable the creation of knowledge: organizational intention, redundancy of information, creative chaos, autonomy, requisite variety and middle managers. Bijlsma-Frankema, Rosendaal and Taminiau (2006) describe in short these factors that were proposed by Nonaka and Takeuchi. Organizational intention means that top - management has the task "to set challenging goals, to design a vision, indicating what knowledge should be developed and a knowledge strategy indicating how to create new knowledge" (Bijlsma-Frankema, Rosendaal and Taminiau, 2006, pp. 293-294). By redundancy of information we must understand that different communication channels are used for informing 
employees. Creative chaos "aims to promote a sense of urgency that heightens attentiveness and a willingness to act upon sub-optimal performance" (Bijlsma-Frankema, Rosendaal and Taminiau, 2006, p. 294). Autonomy implies that employees have space for self-management. Requisite variety "refers to a match between the internal variety of an organization and the complexity of the environment" (Bijlsma-Frankema, Rosendaal and Taminiau, 2006, p. 294). Middle managers have an important role in turning the organizational intention into concrete goals. They also have to design "a conceptual framework that enables employees to make sense of their tacit knowledge and exchange knowledge within the team" (Bijlsma-Frankema, Rosendaal and Taminiau, 2006, p. 294).

Other authors' present factors that enable organizational learning as an overall process: culture, strategy, structure and environment (Fiol and Lyles, 1985 in Bapuji and Crossan, 2004). To these four factors, it is claimed that two other variables appear in the literature: resource position and organizational stage of development (Bapuji and Crossan, 2004). Bapuji and Crossan (2004) centralize some aspects of culture that can be considered facilitators for learning: a participative decision-making culture, learning orientation (Hurley and Hult, 1998 in Bapuji and Crossan, 2004), openness, transformational leadership (Hult et al., 2000 in Bapuji and Crossan, 2004), and positive supervisory behavior, organizational support (Ramus and Steger, 2000 in Bapuji and Crossan, 2004). Among the most important aspects regarding strategy, that can influence organizational learning, is "providing a context for perceiving and interpreting the environment" (Fiol and Lyles, 1985 in Bapuji and Crossan, 2004, p. 406). The structure of an organization can influence organizational learning by the composition and management of groups, by "formal procedures for learning, cross-functional communication and stability of team membership" (Bapuji and Crossan, 2004, p. 407). The environment influences organizational learning because it determines an organization's access to resources related to knowledge, such as talent or collaboration partners. Organizational stage is another element that influences organizational learning. Some companies, for example bio-technology firms, depend, during their early stage of development, on other firms in order to learn while other companies do not learn in their initial phase - for example joint ventures. Resource position can influence learning at organizational level - research suggests that sometimes resource abundance could facilitate learning in some cases but block it in other cases.

Other factors that are considered to influence organizational learning are "contextual factors such as the organization structure, information, communication and control processes, which impact on the way individuals, learn" (Hedberg, 1981; Pawlowski, 2001; Simon, 1991 in Antonacopoulou, 2006, p. 456). 
Giving these examples of factors that can influence organizational learning, managers have to be aware of the facilitating and inhibiting factors and they must undertake actions in order to create conditions for organizational learning processes to take place, to increase the number and, where the case, the intensity of presence for enabling factors and respectively to lower the number and, where the case, the intensity or frequency of presence for inhibiting factors for organizational learning.

For example, managers should create within the organizations that they lead an environment that stimulates creativity, an environment in which employees are encouraged to explore, to ask questions to them, to ask why they have to do certain things. For employees to have an inclination towards learning, managers should encourage them to learn, to collaborate, to share information and knowledge within teams, because organizational learning is a natural stage that follows individual learning and team learning, if the organization creates conditions for enabling learning at organizational level.

Employees are going to explore new solutions; they are going to put to question the operating norms or the values of an organization if they know that certain situations in which they will be implicated are not going to have repercussions towards them. Managers should encourage exploring and learning, with the cost of possible mistakes. The traditional norm is that managers are inclined to apply penalties for those who make mistakes. This creates fear within employees' minds and fear is an inhibitor for learning, for exploring or creating. And, as long as employees do not learn at individual level and at team level, organizational learning is not going to occur.

Employees need to know the reasons for doing what they do. When a person knows the reason beyond a certain task, he or she is more inclined to be consciously and even emotionally involved in working and finishing a certain task. This can also help employees to see beyond a certain situation.

If managers will encourage employees to see beyond certain situations, to put questions to them, to not take for granted the operating norms or values of an organization, they will also help employees to "jump" from knowing-what to knowing-how and even to knowing-why.

These actions that managers can undertake are going to have an impact on individual learning. Then, managers should encourage learning at team level. In order for the learning process to move from the individual level to the team level, managers should induce in their employees' minds that, when working in teams, the final goal is the accomplishment of the task at team level, thus employees should share with their colleagues the knowledge that they have and also to gain new knowledge from their colleagues. At team level, we can consider that it is important for the manager 
to also be a leader or to designate, at team level, employees who have leadership skills, who can inspire other people, who can help them have confidence in themselves.

After creating conditions for team learning to take place, managers must take into consideration actions to be undertaken in order to enable organizational learning processes.

All the actions that managers must undertake that were mentioned for turning a traditional organization into a learning organization could also be applied for enabling organizational learning processes. These actions could be done in steps, meaning that first managers would enable organizational learning processes, and, in time, the organization is going to become a learning organization.

Besides these actions, some other things that managers could do in order to facilitate organizational learning are: promote learning at organizational level, by a learning culture - create norms or procedures to enable learning and include, among the organization's values, aspects regarding knowledge and learning; include employees in decizional processes, communicate in an open and effective way, eliminate the potential barriers that could exist between management and employees.

\section{CONCLUSION}

Knowledge and learning are two central elements for organizations in the context of the knowledge society, the knowledge economy and the actual business environment. In order to face the constant changes that are specific to an unstable business environment, organizations need to develop learning processes at organizational level or even become learning organizations. For a traditional organization to become a learning organization managers need to undertake some changes, they need to make a series of adaptations.

We argue that, although managers can undertake a series of changes for transforming organizations into learning organizations, they should first create conditions for enabling organizational learning processes, and afterwards lead their organizations into becoming learning organizations, because the learning organization is an ideal type of organization, thus the transformation needs to be made gradually.

The research has also some limitations. Taking into consideration that the approach is a theoretical one, in practice it is also necessary to see what the impact of the managerial adaptations in order to transform an organization into a learning organization, and respectively of the conditions that need to be created for enabling organizational learning, would be. Thus, one way to measure 
these could be, for example, to assess the performance, level of innovation and competitive advantages that an organization has before undertaking such actions and at a certain period after certain actions have been undertaken, in order to see if there are differences. This way, managers will know for sure if organizational learning or the learning organizations are answers for being competitive in the actual business environment.

In conclusion, the relationship between the learning organization and the business environment is a mutual one. The need for learning at organizational level is emphasized by the actual business enviroment. On the other hand, learning at organizational level and even turning traditional organizations into learning organizations can lead to competitiveness at organizational level, regional development and help develop the business environment as a whole.

\section{REFERENCES}

Ameli, P., Kayes, D.C. (2011) Triple-loop learning in a cross-sector partnership The DC Central Kitchen partnership, The Learning Organization, vol. 18, no. 3, pp. 175 - 188, accesed on May 2012 at 10.1108/09696471111123243 (Permanent URL).

Antonacopoulou, E.P. (2006) The Relationship between Individual and Organizational Learning:

New Evidence from Managerial Learning Practices, Management Leaning, vol. 37, no. 4, pp. 455-473, accesed on May 2012 at 10.1177/1350507606070220 (Permanent URL).

Argote, L. (2011) Organizational learning research: Past, present and future, Management Learning, vol. 42, no. 4, pp. 439-446, accesed on May 2012 at http://mlq.sagepub.com/content/42/4/439.abstract.

Argyris, C., Schön, D. (1974) Theory in practice: Increasing professional effectiveness, San Francisco, United States of America: Jossey Bass.

Argyris, C., Schön, D.A. (1978) Organisational Learning: A Theory of Action Perspective, New York, United States of America: Addison-Wesley.

Bapuji, H., Crossan, M. (2004) From questions to answers: reviewing organizational learning research, Management Learning, vol. 35, no. 4, pp. 397-417, accesed on May 2012 at 10.1177/1350507604048270 (Permanent URL).

Bijlsma-Frankema, K., Rosendaal, B., Taminiau, Y. (2006) Acting on frictions: learning blocks and flows in knowledge intensive organizations, Journal of European Industrial Training, vol. 30, 
no. 4, pp. 291-309, accesed on May 2012 at 10.1108/03090590610673650 (Permanent URL).

Brătianu, C., Orzea, I. (2008) Strategii pentru implementarea managementului cunoştinţelor în companiile româneşti, Review of General Management, vol. 4, no. 2, pp. 122-137, accesed on May 2012 at http://www.managementgeneral.ro/.

Casey, A. (2005) Enhancing Individual and Organizational Learning. A Sociological Model, Management Learning, vol. 36, no. 2, pp. 131-147, accesed on May 2012 at http://mlq.sagepub.com/content/36/2/131.abstract.

Chiva R., Grandío A., Alegre J. (2010) Adaptive and Generative Learning: Implications from Complexity Theories, International Journal of Management Reviews, vol. 12, no. 2, pp. 114129, accesed on May 2012 at 10.1111/j.1468-2370.2008.00255.x (Permanent URL).

Crossan, M.M., Lane, H.W., White, R.E. (1999) An Organisational Learning Framework: From Intuition to Institution, Academy of Management Review, vol. 24, no. 3, pp. 522-537, accesed on July 2012 at http://www.jstor.org/stable/259140.

Cymanow, P. (n.d.) Analysis of Human Resources of a Learning Organization, accesed on May 2012 at http://baitas.lzuu.lt/ mazylis/julram/7/31.pdf.

Easterby-Smith, M., Crossan, M., Niccolini, D. (2000) Organizational learning: Debates Past, Present and Future, Journal of Management Studies, vol. 37, no. 6, pp. 783-796, accesed on July 2012 at http://onlinelibrary.wiley.com/doi/10.1111/1467-6486.00203/abstract.

Fiol, C. M., Lyles, M. A. (1985) Organizational Learning, Academy of Management Review, vol. 10, no. 4, pp. 803-813, accesed on July 2012 at http://www.jstor.org/stable/258048.

Hayek, F. (1937) Economics and knowledge, Economica IV, pp. 33-54, accesed on July 2012 at http://www.virtualschool.edu/mon/Economics/HayekEconomicsAndKnowledge.html.

Hedberg, B. (1981) How Organisations Learn and Unlearn, in Nystrom, P. and Starbuck, W. (eds.) Handbook of Organisational Design, Volume 1: Adapting Organisations to Their Environment, pp. 3-27, Oxford, United Kingdom: Oxford University Press.

Howitt, P. (1996) On Some Problems in Measuring Knowledge-based Growth, in Howitt, P. (ed.), Implications of Knowledge-Based Growth for Micro-Economic Policies, pp. 9-29, Calgary, Canada: University of Calgary Press.

Hult, G.T.M., Hurley, R.F., Giunipero, L.C., Nichols, E.L. (2000) Organizational Learning in Global Purchasing: A Model and Test of Internal Users and Corporate Buyers, Decision Sciences, vol. 31, no. 2, pp. 293-325, accesed on July 2012 at http://onlinelibrary.wiley.com/doi/10.1111/j.1540-5915.2000.tb01625.x/abstract. 
Hurley, R.F., Hult, G.T.M. (1998) Innovation, Market Orientation, and Organizational Learning: An Integration and Empirical Examination, Journal of Marketing, vol. 62, no. 3, pp. 42-54, accesed on July 2012 at http://www.jstor.org/stable/1251742.

Kerka, S. (1995) The learning organization: myths and realities, Eric Clearinghouse, accesed on July 2012 at http://www.eric.ed.gov/PDFS/ED388802.pdf.

Lant, T. K., Mezias, S. J. (1992) An Organizational Learning Model of Convergence and Reorientation, Organization Science, vol. 3, no. 1, pp. 47-71, accesed on July 2012 at http://orgsci.journal.informs.org/content/3/1/47.short.

Loverde, L. (2005) Learning organizations and quadruple loops of feedback. Part II. Implementation, Ingenierías, vol. III, no. 27, pp. 34-47, accesed on May 2012 at ingenierias.uanl.mx/26/pdfs/26_learning.pdf.

Lytras, M.D., Pouloudi, A. (2003) Project management as a knowledge management primer: the learning infrastructure in knowledge-intensive organizations: projects as knowledge transformations and beyond, The Learning Organization, vol. 10, no. 4/5, pp. 237-250, accesed on May 2012 at 10.1108/09696470310476007 (Permanent URL).

March, J.G., Olsen, J.P. (1976) Ambiguity and Choice in organisations, Bergen, Norway: Universitetsforlaget.

Marshall, J., Smith, S., Buxton, S. (2009) Learning organisations and organisational learning: What have we learned?, Management Services, vol. 53, no. 2, pp. 36-44, accesed on May 2012 at http:/www.ims-productivity.com/user/custom/journal/2009/summer/MSJ18Summer-2009.pdf.

Murray, P., Donegan, K. (2003) Empirical linkages between firm competencies and organisational learning, The Learning Organization, vol. 10, no. 1, pp. 51-62, accesed on May 2012 at 10.1108/09696470310457496 (Permanent URL).

Nonaka, I. (1994) A Dynamic Theory of Organizational Knowledge Creation, Organization Science, vol. 5, no. 1, pp. 14-37, accesed on May 2012 at 10.1287/orsc.5.1.14 (Permanent URL).

Nonaka, I., Konno, N. (1998) The Concept of „Ba”: Building a Foundation for Knowledge Creation, California Management Review, vol. 40, no. 3, pp. 40-54, accesed on May 2012 at http://www.jstor.org/stable/41165942.

Nonaka, I., Takeuchi, H. (1995), The Knowledge Creating Company: How Japanese companies create the dynamics of innovation, New York, United States of America: Oxford University Press. 
Oxley, L., Walker, P., Thorns, D., Wang, H. (2008) The Knowledge Economy/Society: The Latest Example of "Measurement Without Theory"?, The Journal of Philosophical Economics, vol. 11, no. 1, pp. 20-54, accesed on May 2012 at http://www.jpe.ro/poze/articole/16.pdf.

Pawlowsky, P. (2001) The Treatment of Organizational Learning in Management Science, in

Dierkes, M., Antal, A.B., Child, J. and Nonaka, I. (eds.) Handbook of Organizational Learning and Knowledge, pp. 61-88, Oxford, United Kingdom: Oxford University Press.

Powell, W.W., Snellman, K. (2004) The Knowledge Economy, Annual Review of Sociology, vol. 30, pp. 199-220, accesed on May 2012 at 10.1146/annurev.soc.29.010202.100037 (Permanent URL).

Ramus, C.A., Steger, U. (2000) The Roles of Supervisory Support Behaviors and Environmental Policy in Employee "Ecoinitiatives" at Leading-edge European Companies, Academy of Management Journal, vol. 43, no. 4, pp. 605-626, accesed on July 2012 at http://amj.aom.org/content/43/4/605.abstract.

Senge, P.M. (2006) The Fifth Discipline: The Art and Practice of the Learning Organization, New York, United States of America: Doubleday.

Senge, P.M. (1990) The Fifth Discipline. The art and practice of the learning organization, London, United Kingdom: Random House.

Sessa, V.I., London, M., Pingor, C., Gullu, B., Patel, J. (2011) Adaptive, generative, and transformative learning in project teams, Team Performance Management, vol. 17, no. 3/4, pp. 146 - 167, accesed on May 2012 at 10.1108/13527591111143691 (Permanent URL).

Simon, H.A. (1991) Bounded Rationality and Organisational Learning, Organisation Science, vol. 2, no. 1, pp. 125-134, accesed on July 2012 at 10.1287/orsc.2.1.125 (Permanent URL).

Sitkin, S.B. (1996) Learning through failure, in Cohen, M. and Sproull, L. (eds.): Organizational Learning, pp. 541-577, California, United States of America: Sage Publications.

Smith, M.K. (2001) The learning organization, The encyclopedia of informal education, accesed on May 2012 at http://www.infed.org/biblio/learning-organization.htm.

Tiwana, A. (1999) The Knowledge Management toolkit, Atlanta, United States of America: Prentice Hall.

Tsang, E.W.K. (1997) Organizational learning and the learning organization: a dichotomy between descriptive and prescriptive research, Human Relations, vol. 50, no. 1, pp. 73-89, accesed on July 2012 at http://hum.sagepub.com/content/50/1/73.abstract. 
Virany, B., Tushman, M., Romanelli, E. (1992) Executive succession and organization outcomes in turbulent environments: An organization learning approach, Organization Science, vol. 3, no. 1, pp. 72-91, accesed on July 2012 at http://orgsci.journal.informs.org/content/3/1/72.short.

Välimaa J., Hoffman D. (2008) Knowledge society discourse and higher education, Higher Education, vol. 56, no. 3, pp. 265-285, accesed on May 2012 at 10.1007/s10734-008-9123-7 (Permanent URL).

Wang, C.L., Ahmed, P.K. (2003) Organisational learning: A critical review, The Learning Organization, vol. 10, no. 1, pp. 8-17, accesed on May 2012 at 10.1108/09696470310457469 (Permanent URL). 